\title{
A CONSTITUIÇÃO DO PROFESSOR DE INGLÊS PRÉ-SERVIÇO EM UM CURSO DE LETRAS EAD: REPRESENTAÇÕES SOBRE FORMAÇÃO, ENSINO-APRENDIZAGEM E TECNOLOGIA
}

\author{
Cristiane Carvalho de Paula Brito* \\ Maria de Fátima Fonseca Guilherme ** \\ Universidade Federal de Uberlândia \\ Instituto de Letras e Linguística \\ Uberlândia, MG, Brasil
}

\begin{abstract}
Resumo: Este trabalho visa, a partir de uma perspectiva discursiva de linguagem em interface com os estudos em Linguística Aplicada, a investigar representações construídas em dizeres de professores pré-serviço acerca do processo de formação e de ensinoaprendizagem de língua inglesa em um curso de licenciatura de Letras-Inglês (LI) a distância. Os resultados apontam que os participantes enunciam de um lugar de entremeio, marcado pelo embate entre a posição sujeito-professor pré-serviço de LI em curso presencial $e$ a posição sujeito-professor pré-serviço de LI em curso EaD. Nesse embate, eles se inscrevem no discurso da autonomia, da seletividade, da falta e da excelência da tecnologia, os quais funcionam de forma a criar efeitos de verdade que obliteram os aspectos contraditórios e conflitivos constitutivos da relação sujeito-linguagem-tecnologia.
\end{abstract}

Palavras-chave: Discurso. Tecnologia. Formação docente.

\section{INTRODUÇÃO}

Este trabalho visa discutir representações de professores pré-serviço ${ }^{1}$ sobre sua formação e seus processos de ensino-aprendizagem, tendo em vista a relação que estabelecem com as TICs (Tecnologias de Informação e Comunicação), em um curso de licenciatura de Letras-Inglês em contexto de educação a distância (EaD), em uma instituição federal de ensino superior (IFES) no estado de Minas Gerais.

O referido curso, desenvolvido no período de 2011 a 2015, advém do Plano Nacional de Formação de Professores da Educação Básica (PARFOR), o qual se constitui em um programa emergencial cujo objetivo é oferecer formação em ensino superior para professores que atuam na educação básica na rede pública. $\mathrm{O}$ curso aconteceu na

\footnotetext{
* Doutora em Linguística Aplicada pela Universidade Estadual de Campinas. E-mail: depaulabrito@gmail.com

** Doutora em Linguística Aplicada e Estudos da Linguagem pela Pontifícia Universidade Católica de São Paulo. E-mail: mffguilherme@gmail.com

${ }^{1}$ Utilizaremos os termos 'professores pré-serviço' e 'professores em formação' para nos referirmos aos licenciandos participantes deste estudo.
} 
modalidade a distância, na plataforma Moodle, em quatro polos, contou com o trabalho de tutores presenciais e a distância e os materiais utilizados (Guia de Estudos e videoaulas) foram produzidos pelos docentes que participaram do programa.

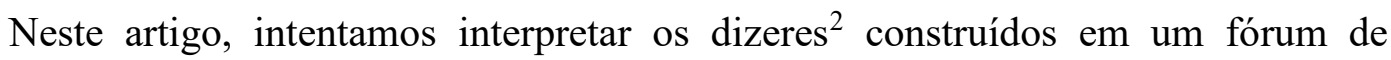
discussão da disciplina 'As novas tecnologias da informação e comunicação no ensino de LI', ministrada ao final do curso. Para isso, fundamentamo-nos no quadro teóricometodológico da Análise do Discurso (AD) pêcheutiana, nos estudos desenvolvidos pelo Círculo de Bakhtin e nos trabalhos da Linguística Aplicada (LA). Interessa-nos, portanto, ao realizar atravessamentos teóricos entre Pêcheux, Bakhtin e os estudos em LA, tomar a linguagem em sua dimensão sócio-histórico-ideológica e dialógico-polifônica para refletir sobre a relação sujeito-linguagem-tecnologia, no intuito de problematizar as possíveis incidências dos discursos que se constituem em um ambiente virtual de formação de professores para as (futuras) práticas docentes desses sujeitos.

Entendemos que os professores pré-serviço representam seus lugares nos processos discursivos instaurados no ambiente virtual em análise, ou seja, deixam vir à tona formações imaginárias que funcionam designando os lugares que eles atribuem a si e ao outro, a imagem que fazem do seu próprio lugar e do lugar do outro (PÊCHEUX, 1969/1997). Dessa forma, é da investigação dessas formações imaginárias, compreendidas como representações, que parte a proposta de realização deste estudo.

Ademais, cremos que a análise de representações pode contribuir para a compreensão de discursividades construídas em EaD no ensino superior, ao nos permitir questionar os sentidos que se cristalizam e se naturalizam, assumindo efeito de verdade e impondo, desse modo, lugares sócio-históricos para esses professores em formação em sua relação com as TICs e com os processos de ensino-aprendizagem de LI. Salientamos que tomamos discursividade como

um processo que explicita, em seu caráter sócio-histórico-cultural e ideológico, a dinâmica de produção de sentidos para contemplar as ações de ensinar e aprender, considerando o sujeito sob o aspecto da posição em constante movência de percepções e perspectivas de olhar o outro e os objetos em seu ethos de atuação socioeducacional e profissional. (GUILHERME, 2009, p. 24)

Há de se ressaltar ainda a particularidade do curso, uma vez que tem como objetivo "formar profissionais com proficiência em língua inglesa, com a capacitação em todas as habilidades (escrita, fala, compreensão oral e leitura) de maneira a preparar os alunos para serem professores de excelência na educação básica" (HASHIGUTI; BRITO, 2014, p. 92). Assim, o professor em formação em um curso de Letras-Inglês em modalidade nãopresencial se vê interpelado a construir uma posição identitária e identificatória, um espaço de enunciabilidade que o legitime como enunciador de uma língua outra, no/pelo espaço outro (o virtual), considerando o que seja aprender/ser professor de LI no Brasil.

Para dar conta da reflexão aqui proposta, organizamos o artigo da seguinte forma: no primeiro momento, faremos uma breve discussão do escopo teórico que respalda nosso

\footnotetext{
${ }^{2} \mathrm{O}$ termo 'dizer' é usado aqui para se referir à materialidade linguística em análise, ou seja, é da ordem do intradiscurso.
} 
gesto de interpretação do corpus. Em seguida, explicitaremos nosso percurso metodológico e discutiremos a análise empreendida. Finalmente, tentaremos alinhavar alguns fios que problematizem a relação do sujeito em formação com as TICs na medida em que os cursos a distância têm se configurado em uma realidade contemporânea, estabelecendo outras ordens do discurso e, concomitantemente, construindo memórias discursivas que balizarão a futura prática desses professores.

\section{REDE DISCURSIVA E A RELAÇÃO LINGUAGEM-SUJEITO-TECNOLOGIA}

As confluências epistemológicas entre as redes conceituais bakhtiniana e pêcheutiana são aqui tomadas "como a possibilidade de se lançar um olhar para duas correntes teóricas singulares, mas que, em alguns momentos, constroem percepções convergentes acerca de determinados conceitos e noções" (GUILHERME, 2013, p. 259) ${ }^{3}$.

Ao nos inscrevermos em um lugar de interface entre os estudos do discurso sobretudo nos trabalhos de Bakhtin (1920/2010), Bakhtin/Voloshinov (1929/2002) e Pêcheux $(1969 / 1997$, 1975/1997) - e os estudos da LA, em sua perspectiva trans/indisciplinar e transgressiva, conforme postulado por Kleiman (2013), Bohn (2005), Moita Lopes (2006), Pennycook (2006), dentre outros, propomo-nos a compreender os processos de formação de professor e de ensino-aprendizagem de línguas de forma a mobilizar concepções como as de sujeito, linguagem, sentido e memória discursiva, a fím de refutar a língua em sua transparência e trabalhar com a noção de discurso, equívoco, contradição e heterogeneidade.

Trata-se, pois, de defender que a formação do professor e o ensino-aprendizagem de línguas extrapola um conjunto de saberes ou competências adquiridos por um sujeito, antes dizem respeito a "um processo contínuo de (des)inscrição em discursos sóciohistoricamente constituídos, de (des)identificações com memórias discursivas, na e pela linguagem" (BRITO; GUILHERME, 2013, p. 25).

Entendemos que essa interface contempla o exercício de uma LA que se pretende ser socialmente comprometida, responsável e responsiva à vida social, ou seja, uma LA que busca problematizar questões de uso da linguagem para que se possa melhor compreendê-las, uma LA que propõe intervenções e que se compromete com sujeitos que vivenciam problemas nas diversas situações mediadas pela linguagem e que devem ser reteorizados a partir de "sua heterogeneidade, fluidez e mutações, atrelando a esse processo os imbricamentos de poder e desigualdade inerentes" (MOITA LOPES, 2009, p. 21). Enfim, uma LA que, no século XXI, se vê marcada pelo questionamento de "suas próprias bases filosóficas, suas concepções de linguagem e de sujeito, enfim, sua forma de fazer ciência" (BRITO; GUILHERME, 2013, p. 22).

Cumpre ainda dizer que este lugar de interface que aqui aventamos nos permite trabalhar com a perspectiva de sujeito social defendida por Moita Lopes atrelada a uma visão de sujeito perpassada pelo inconsciente, e, portanto, cindido e fragmentado, que se significa e produz sentidos não por sua soberana vontade ou escolha, mas pela sua tomada de posição - movimentos de identificação - a qual se dá pela sua inscrição em lugares discursivos.

\footnotetext{
${ }^{3}$ Para exemplos de estudos que contemplam esta confluência, ver Santos et al. (2003), Gregolin (2006). 
Trata-se, pois, de um sujeito que é interpelado e evoca memórias ao enunciar, ou seja, na perspectiva discursiva aqui contemplada, a noção de sujeito requer a compreensão do processo subjetivo, que diz respeito à imbricação da língua(gem), da história e do inconsciente, em que "a linguagem (ou jogo, ou ordem do signo, ou o discurso) não é entendida como uma origem, ou como algo que encobre uma verdade existente independentemente dela própria, mas sim como exterior a qualquer falante" (HENRY, 2010, p. 30). Isso significa que o sujeito é chamado à existência por meio da interpelação que se dá via linguagem. Esta, por sua vez, corresponde ao lugar em que se pode captar o sujeito que diz e o sujeito que é dito. Nesse sentido, isto possibilita-nos dizer que ele é visto, no viés discursivo, enquanto "efeito ideológico elementar" (HENRY, 2010, p. 31), pois "nada se torna um sujeito, mas aquele que é 'chamado' é sempre já-sujeito" (HENRY, 2010, p. 91).

Tendo em vista que internacionalmente existe uma convergência nas políticas governamentais de informatização e criação de redes digitais e que "os governos no mundo inteiro estão preocupados em possibilitar o acesso às tecnologias digitais a todas as camadas das populações, especialmente, no setor educacional" (PAIVA, 2010, p. 2) ${ }^{4}$ e que as tecnologias instauram relações de poder-saber, entendemos que é necessário problematizar as condições sócio-históricas que incidem naquilo que pode ou não ser dito acerca da relação sujeito-linguagem-tecnologia, sobretudo no que concerne a questões ligadas ao ensino-aprendizagem de línguas. Desse modo, as inovações tecnológicas, mais do que meras ferramentas a serem usadas nos processos educacionais, adquirem o status de saber-poder (e saber-fazer) e interpelam os sujeitos a significá-las, sendo que, ao realizarem uma clivagem ${ }^{5}$ do papel dessas inovações tecnológicas em seu processo de formação, identificam-se com discursos que, por sua vez, corroboram ou deslocam efeitos de sentido acerca dessas inovações.

Lima e Mascia (2011) analisam o Discurso Político Educacional vigente em documentos do MEC sobre a EaD no intuito de avaliar a concepção de sujeito. Apesar de a $\mathrm{EaD}$ se configurar como um elemento inovador dentro do discurso educacional, as referidas autoras argumentam que as relações de poder-saber permanecem inalteradas, não havendo, pois, a emergência de uma nova concepção de sujeito, "o único efeito de novo se dá pela emergência do veículo, ou seja, o virtual" (p. 281).

Os dizeres que aqui tomamos para análise nos interessam por refletirem e refratarem vozes sociais oriundas do movimento dos sentidos na história, as quais são evocadas pelos sujeitos produzindo neles a ilusão de serem a origem do que dizem - ao que Pêcheux (1975/1997) denomina esquecimento n.1. O efeito de evidência provocado pela ideologia apaga a relação da língua com a história, escamoteando a equivocidade dos sentidos.

\footnotetext{
${ }^{4}$ Paiva (2010) aponta como exemplos de políticas educacionais voltadas ao desenvolvimento tecnológico o projeto ENLACES do Chile (iniciado em 1993 com foco no ensino primário e secundário e na capacitação de professores); o projeto World Links (com início em 1997 e voltado para a inclusão digital de alunos e professores em países em desenvolvimento); e as políticas do MEC no Brasil (tais como a UAB, o Portal da CAPES, o ProInfo etc).

5 Tomamos clivagem como uma "triagem de sentidos feita pelo sujeito, considerando seus referenciais intra-epistemológicos e sócio-histórico-culturais. Trata-se, pois, de uma filtragem de sentidos realizada pelos sujeitos, tomando por parâmetro uma relativização entre os seus referenciais discursivos e os sentidos que são expostos na dinâmica dos processos interativos" (SANTOS, 2000, p. 206).
} 
Entendemos que os dizeres refletem e refratam, na medida em que, segundo Bakhtin/ Volochinov (1929/2002), "um signo não existe apenas como parte de uma realidade; ele também reflete e refrata uma outra (p. 32), ou seja, os signos ideológicos (os dizeres enunciados pelos professores em formação) refletem e refratam a realidade, o que significa que refletem a realidade e a interpretam, fazendo, assim, refrações da realidade, ao mesmo tempo que esses signos são traspassados por ideologias que são construídas nessa realidade.

Investigar as representações construídas, na e pela linguagem, acerca do que seja ser/tornar-se professor de LI em EaD e dos processos de ensino-aprendizagem dessa língua, implica, pois, compreender o funcionamento da malha discursiva na qual os sujeitos se inscrevem para (se)significar.

Ruiz (2013) discute como materiais didáticos usados em cursos de Letras, na modalidade a distância, representam o aluno ora como aquele que não sabe/não detém o conhecimento (e, portanto, precisa alcançá-lo), ora como aprendiz autônomo, capaz de controlar, monitorar e tomar as decisões acerca de seu processo de ensino-aprendizagem. A autora argumenta que esse embate de representações é possível quando se compreende que o discurso pedagógico refrata as vozes sociais, econômicas, políticas e ideológicas de forma a posicionar o aluno em concordância com as diretrizes de um mundo globalizado, regido pelo capital, que atenda às demandas do mercado atual, o qual passa a exigir um "trabalhador altamente qualificado, versátil, flexível, capaz de atuar nas mais diferentes áreas, de acordo com a necessidade do mercado e, acima de tudo, capaz de solucionar problemas" (p. 302).

Silva e Brito (2015), ao analisarem a discursividade sobre o ensino e aprendizagem de línguas estrangeiras mediadas pelas TICs em periódicos da LA, salientam como o efeito de evidência da tecnologia é asseverado pelo discurso da essencialidade tecnológica, cujo funcionamento se dá pela naturalização da necessidade de se contemplar o uso das TICs nos processos de ensino-aprendizagem. Além do discurso da essencialidade tecnológica, elas apontam a emergência do discurso: da inovação, o qual propala sentidos de mudança e transformação com o advento das TICs; da interação, que atribui às TICs a potencialização da aprendizagem colaborativa; e o da agentividade, que postula a liberdade e necessidade do sujeito de produzir conhecimentos com o uso das TICs, por meio de uma postura ativa.

As autoras supracitadas defendem que esses discursos se sustentam em distintas representações de aluno, professor, ensino-aprendizagem, linguagem, tecnologia, dentre outras, e funcionam de forma a apagar a heterogeneidade dos sujeitos, as determinações históricas e institucionais que perpassam os processos de ensino-aprendizagem, escamoteando, assim, os embates e tensões constitutivos das relações que se dão entre os sujeitos na e pela linguagem.

Tavares e Chagas (2012) problematizam a incidência do discurso das novas tecnologias na constituição identitária do professor de línguas e argumentam que, por se revestir de um caráter de indispensabilidade, permeado por uma lógica pós-moderna, tal discurso relativiza o saber suposto no professor, apagando "o investimento subjetivo e o saber que precisam ser mobilizados e investidos em uma relação pedagógica” (p. 13). 
Portanto, a nosso ver, problematizar discursividades produzidas/reproduzidas no ambiente de ensino-aprendizagem pode contribuir para uma formação cidadã e democrática, "vinculada à problematização das próprias ideias de democracia e cidadania em meio aos processos de globalização contemporâneos" (ROCHA; MACIEL, 2015, p.18). Trata-se, antes de tudo, de defender, na esteira do pensamento bakhtiniano e freiriano, a formação de professores como ato responsável (SZUNDY, 2014), fruto de uma concepção de educação que extrapola visões meramente tecnicistas e possibilita aos sujeitos o engajamento na transformação das práticas sociais. Por isso, segundo Szundy (2014), cabe à escola questionar a estabilidade dos significados para transformá-los, desenvolvendo nos alunos uma postura crítica perante escolhas sempre situadas. A autora acrescenta ainda que, em um contexto em que aprendizes circulam pelos novos letramentos digitais e se tornam cada vez mais produtores de significados na rede, devem os professores desconstruir significados e orientar as escolhas verbais e não verbais de forma a desvelar os significados refratados a partir das escolhas realizadas $\mathrm{e}$ problematizar de que forma significados que causam sofrimento, exclusão ou revelam preconceitos podem ser reconstruídos de forma mais crítica e ética.

\section{DISCURSOS EM REDE: SOBRE A CONSTITUIÇÃO DO CORPUS}

Os dizeres que constituem o corpus da pesquisa realizada foram coletados no fórum de discussão intitulado Me, a pre-service English teacher in a distance course, proposto no início da disciplina de sétimo período 'As novas tecnologias da informação e comunicação no ensino de LI', em 2014, sendo 25 professores pré-serviço participantes. A disciplina tinha como principais objetivos: (i) discutir a concepção de TICs, sob uma perspectiva discursiva; (ii) problematizar a ideia de 'nativo digital' $x$ 'imigrante digital'; (iii) discutir a aprendizagem de LI como prática transgressiva e sua relação com as TICs; e (iv) desenvolver um projeto de ensino de LI contemplando o uso de TICs para propósitos pedagógicos.

No quadro 1, mais adiante pode-se ver como o fórum em questão foi proposto no ambiente virtual. Nosso percurso metodológico consiste na investigação das regularidades ${ }^{6}$ que emergem nos dizeres quando os professores pré-serviço enunciam sobre sua experiência de cursar uma licenciatura em Letras-Inglês na modalidade a distância. Após uma primeira leitura desses dizeres, selecionamos as sequências discursivas $^{7}$ (SD) que, a nosso ver, apontam sentidos que ressoam os já-ditos (memória discursiva), trazendo à baila as inscrições discursivas dos sujeitos. Trata-se, pois, de pensar na relação do interdiscurso com o intradiscurso, ou seja, nas redes de sentido nas quais os sujeitos se filiam e que irrompem na materialidade linguística.

\footnotetext{
${ }^{6}$ Regularidades são aqui tomadas como "evidências significativas, observadas na conjuntura enunciativa da manifestação discursiva em estudo. Essas evidências aparecem como elementos de recorrência, de idiossincrasia enunciativa, ou ainda, de efeito provocado pela natureza de organização dos sentidos" (SANTOS, 2004, p. 114).

${ }^{7}$ Segundo Santos (2004, p. 114), sequências discursivas "representam conjuntos de enunciados recortados do escopo da manifestação em estudo, que sinalizam uma evidência por recorrência, particularidade ou efeito, e passam a constituir unidades-base de análise".
} 


\section{Quadro 1 - Task 7: Forum - Me, a pre-service English teacher in a distance course ${ }^{8}$}

\section{Task 7: Forum - Me, a pre-service English} teacher in a distance course

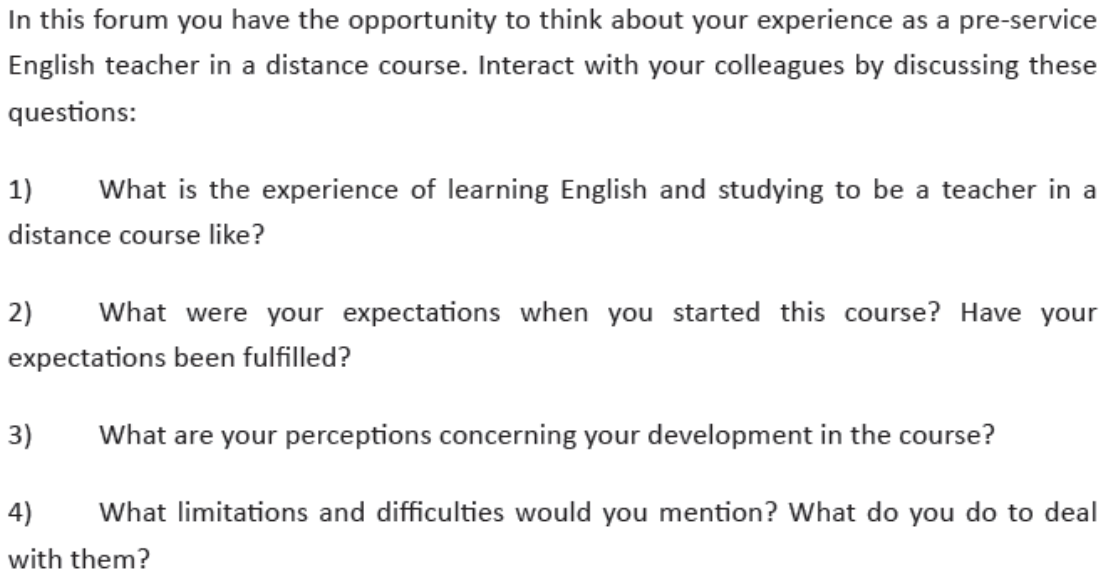

Fonte: Brito; Hashiguti; Peixoto, 2015, p. 43.

Outro aspecto a se considerar são as condições de produção dos dizeres que constituem o corpus. A enunciação em um fórum institucional mobiliza uma série de formações imaginárias que incide na tomada de posição e na formulação dos dizeres pelos sujeitos. Não se pode, pois, ignorar o auditório social ${ }^{9}$, ou seja, ignorar que se escreve para interagir, para construir sentidos, mas também para responder a uma demanda institucional - no caso, a solicitação para que se fale das experiências como professor em formação em um curso a distância. Ao compreendermos que a interação verbal é a verdadeira substância da língua, que toda palavra é orientada a um interlocutor (BAKHTIN, 1929/2002) e que entra em funcionamento nos processos discursivos um jogo de projeções do lugar que se faz de si e do outro (PÊCHEUX, 1969/1997), precisamos levar em conta que esse sujeito escreve não apenas para seu par, mas também para o tutor (que é quem faz toda a mediação) e, de certa forma, para o professor (que não faz a mediação, porém acompanha as postagens e demais atividades na plataforma virtual). Isto é, escreve-se para um outro com o qual se estabelece uma relação assimétrica - é um outro leitor, mediador, avaliador.

\footnotetext{
${ }^{8}$ Deveriam ser observados os seguintes critérios de avaliação para a referida tarefa: pertinência da resposta; nível de interação com os colegas; uso de linguagem acadêmica; e cumprimento do prazo de entrega da atividade.

${ }^{9}$ Numa perspectiva bakhtiniana, ao contemplarmos o auditório social, "destacamos o crivo da alteridade, destacando-o enquanto fator de tomada de decisão do sujeito em sua inscrição discursiva no universo enunciativo de uma língua estrangeira em estudo" (GUILHERME; SANTOS, 2014, p. 57).
} 
Levar em conta o auditório social e as condições de produção dos dizeres implica não tomar a língua em sua transparência e sim em sua natureza sócio-histórica, como prática situada, e os sentidos sempre como relação $a$.

\section{DESTECENDO A REDE: GESTOS DE INTERPRETAÇÃO}

Ao falarem sobre suas experiências como professores pré-serviço de LI em um curso a distância, os sujeitos parecem enunciar de um lugar de entremeio, marcado pelo embate entre a posição sujeito-professor pré-serviço de LI em curso presencial e a posição sujeito-professor pré-serviço de LI em curso EaD. Nesse lugar, diferentes memórias discursivas são evocadas e ressignificadas, fazendo emergir, no fio do dizer, a contradição, a tensão, enfim o conflituoso batimento oriundo do ser-estar-ocupar distintas posições. Portanto, a partir da leitura e análise dos dizeres, buscamos os discursos que sustentam as representações construídas pelos sujeitos sobre sua formação e seus processos de ensino-aprendizagem, tendo em vista a relação que estabelecem com as TICs.

Aventamos a hipótese de que a posição sujeito-professor pré-serviço de LI em curso presencial mobiliza sentidos que são da ordem da tradição, a qual pode ser tomada tanto como aspecto de conservadorismo quanto de legitimação. Isto é, se, por um lado, os dizeres contemporâneos sobre a relação 'TICs e educação' circunscrevem os cursos presenciais e que não fazem uso de recursos tecnológicos no lugar do velho/antigo e ultrapassado - em contraposição ao aspecto inovador das TICs -; por outro, e em especial quando se considera o ensino superior, não se pode ignorar que a 'novidade' de cursos universitários a distância pode colocá-los em um lugar de incerteza, de devir, ou seja, de expectativa de que venham a ter êxito. Acresce-se a isso a especificidade do curso no que se refere ao desenvolvimento da língua estrangeira, interpelando esse sujeito a não apenas se constituir como professor, mas a construir uma posição identitária em que se veja como enunciador de uma língua outra. Posição essa que não se dá por uma suposta instrumentalização - pela aquisição de um código linguístico, mas pela (des)estabilização de uma estrutura subjetiva, haja vista que "a língua estrangeira vem questionar a relação que está instaurada entre o sujeito e sua língua” (REVUZ, 1998, p. 220).

Por fim, cumpre salientar que esses discursos não são estanques ou unívocos, antes se referem à ordem do imaginário, a sentidos que vão se cristalizando de forma a assumir efeito de verdade. Dito de outro modo, somente se pode atribuir sentidos a essas posições da perspectiva de uma 'relação a', levando em conta a (des)continuidade do movimento linguagem-história-sentido. É, pois, no batimento dessas posições - permeadas por distintas memórias e, portanto, sempre tensas e afetadas pela equivocidade - que o sujeito significa a relação com as TICs em sua formação. 
As representações sobre a formação em Letras se sustentam em dois discursos predominantes que aqui denominamos: o discurso da autonomia e o discurso da seletividade.

O discurso da autonomia traz à baila a representação de que o curso de formação em EaD está 'livre' de certas restrições comuns aos cursos presenciais, proporcionando a tão clamada 'autonomia' do professor, um dos pilares da discursividade científicopedagógica, e em especial da que se volta ao ensino de línguas mediado por tecnologia (PAIVA, 1999; LUZ, 2009; WHITE, 2003). Esse discurso pode ser sintetizado no enunciado o curso de formação em EaD me permite fazer minhas próprias escolhas, como se vê nas sequências abaixo:

(SD01) I'm talking about the development of the student's autonomy. From the moment the apprentice begins to study until the end of his graduation (and even for a lifetime) he is challenged to explore the whole virtual knowledge available ${ }^{10}$. (Jairo ${ }^{11}$ )

(SD02) The experience of learning English and studying to be a teacher in a distance at CEaD give me freedom to focus on my studies and to interact with classmates and faculty, both in and out of the classrooms. (Socorro)

(SD03) The Concise Oxford Dictionary defines autonomy as the ability to govern themselves by their own means. /.../ Because the simple fact that students in the context of EAD, does not mean that we are autonomos. /.../ autonomy comes with the tools /.../ (Milena)

(SD04) /.../ because we know that it isn't easy and we need to be our own teacher, of course that we have our tutors, teachers, etc, that help us, but it depends on us to go on. (Ingrid)

(SD05) And the best thing is to study the time that fit, need not face transit to attend classes and be part of a university course in the comfort of home that makes a difference. (Elza)

(SD06) /.../ my greatest difficulty was to study alone and dealing with a different form of study I was used to /.../ (Carmen)

(SD07) In principle, the advantage of distance learning was to gain time, no need to travel daily to the university, be able to study and complete it in a best possible way /.../ (Laura)

(SD08) Studying at home is great, because we can organize our time the way it suits us. (Carla)

(SD09) But we have to agree that is really comfortable and convenient to be updated without leaving home. (Rute)

O discurso da autonomia se constitui no batimento entre o 'saber-poder' e o 'saberfazer', ou seja, os enunciados evocados nas SDs parecem deslizar do campo pedagógico para trazer à tona dizeres que remetem à interdiscursividade neoliberal, em que se associa o processo educacional à ideia de qualidade e custo/benefício. Dessa forma, a noção de autonomia como capacidade para se autogovernar (SD03), be our own teacher (SD04) ou study alone (SD06) imbrica-se à ideologia de que a EaD proporciona aos sujeitos liberdade (SD02) para controlar o tempo (SD05, SD08) e determinar o espaço (SD05, SD09), construindo assim novas significações acerca dos processos de ensinoaprendizagem. Produz-se, assim, o efeito de que os recursos tecnológicos otimizam,

\footnotetext{
${ }^{10}$ As sequências foram transcritas tais como escritas pelos sujeitos.

${ }^{11}$ Os nomes aqui utilizados são fictícios.
} 
favorecem, facilitam, operacionalizam o investimento do sujeito, in a best way possible (SD07), sendo possível estudar, sem o constrangimento, inclusive, de enfrentar trânsito (SD05, SD07).

Nossa análise parece fazer coro com as considerações de Lima e Mascia (2011), ao apontarem o funcionamento de dois discursos predominantes nos documentos do MEC sobre a $\mathrm{EaD}$, a saber: o discurso enquanto ação e o discurso da qualidade. $\mathrm{O}$ primeiro corrobora o efeito de sentido de mudança e progresso; o segundo, pautado na preocupação extrema com a questão da qualidade, inscreve-se na ideologia liberal e postula a busca pela melhoria e democratização da educação - com vistas a produzir indivíduos competentes para atender ao mercado de trabalho. Nas palavras das autoras,

o discurso neoliberal como um dos grandes "regimes de verdade" que atravessam o discurso da EaD, uma vez que o efeito de sentido de "qualidade total" norteia todo o discurso, sendo um dos pontos principais de reincidência e a grande preocupação apresentada pelo documento. (LIMA; MASCIA, 2011, p. 280. Destaques das autoras)

A nosso ver, dois aspectos merecem atenção quanto à inscrição dos sujeitos no discurso da autonomia. O primeiro se refere ao fato de que ele parece apontar para a dificuldade em problematizar as experiências de ensino-aprendizagem no ambiente virtual, voltando-se, em vez disso, às questões logísticas, relativas aos recursos, planejamento e organização pessoais que acenam a possibilidade mesma de ser/estar na posição de professor de LI em formação. O segundo aspecto diz respeito à constituição identitária dos sujeitos, os quais se veem diante da necessidade de responder da posição de um sujeito pós-moderno cuja identidade se estabelece na relação com o digital, deixando vir à baila o desejo de completude de ser/estar em vários lugares.

Dessa forma, o discurso da autonomia corrobora a ilusão de completude do sujeito, obliterando o fato de que sua 'liberdade de escolha' submete-se a injunções sóciohistórico-ideológicas, institucionais, pedagógicas (e por que não dizer tecnológicas?) que, por sua vez, determinam, em grande medida, as (im)possíveis enunciabilidades e as próprias práticas de linguagem que se desenvolvem nesse espaço de formação. Aliás, no próprio fio do dizer, nota-se a contradição entre a crença no 'poder tudo' em contraposição à percepção de um 'fazer solitário', o que faz com que a experiência autônoma - de ensinar-aprender a distância seja tida como desafio (SD01), pois coloca a responsabilidade da aprendizagem no sujeito (SD04). Essa contradição dá espaço chama à existência, funciona dialogicamente, quase que como uma resposta - ao discurso da seletividade.

O discurso da seletividade, por sua vez, pode ser representado pelo enunciado $o$ curso de formação em EaD não é para qualquer pessoa. Vejamos as sequências:

\footnotetext{
(SD10) It's a quite different experience for me studying through a virtual environment /.../ before starting our course, I was unconfident about the effectiveness of this method. /.../ Certainly there is a long road ahead, many challenges and difficulties to be overcome by this type of education, but I think that this is really something promising /.../ (Jairo)

(SD11) Many people said I'm mad when I say that distance course is better than classroom course. /.../ in a distance course we must have discipline. I developed my english in this course being self-taught and I learned with my classmates too. (Daniel)
} 
(SD12) I completely agree with you when you say that in a distance course, we must have more discipline to conduct our studies. (Jairo)

(SD13) Studying English in the distance is a challenge, but it was an experience where I found difficulties to use a virtual environment, but I developed well the skills to interact with this technology. (Margarida)

(SD14) The experience in a distance course is pretty intense and a challenge everyday, cause we need to be organized, committed, responsible, active, persistence, fulfill all the established deadlines, develop independent learning skills, etc. and if someone doesn't have this profile I think that's better to join in a conventional course. (Ingrid)

(SD15) But I think that the distance course isn't for everyone, it's necessary to have the right profile /.../ (Ingrid)

(SD16) /.../ I repeat this course is for someone that really is responsible, organized, committed, active, persistence, /.../ a lot of people gave it up, because it's very difficult to force yourself to have this commitment at home. (Ingrid)

(SD17) To achieve this in a distance course demands to deal with the challenges of organization, discipline, responsibility, persistence, deadlines. I believe a distance course is not for everyone, I mean, the learner needs to fulfill a profile which involves the characteristics mentioned above. (Rute)

(SD18) /.../ we need to be organized, commited, responsible, etc, to be in a distance course /.../ a distance course may not be the first option for the ones who are too young or the ones who need to develop these characteristics. (Rute)

(SD19) A distance course requires dedication, responsibility, autonomy, etc. (Milena)

(SD20) /.../ distance course is not for everyone. Is necessary have an appropriate profile. So autonomy, establish goals, objectives are very important for that if can obtain success. (Milena)

(SD21) I started this course surrounded of doubts, now I am completely sure about my expectations, mainly about my growth at English /.../ this course is to people that like to independence like me. Although all day be necessary studying and have commitment about all activities. (Sabrina)

(SD22) Unfortunately there are prejudiced about ead /.../ in distance course the student needs be more responsible than in a presencial. (Sabrina)

(SD23) Contrary to what many people think they do a distance course is not easy. For those who like to study and loves challenges and ideal course EAD /.../ I got used to the pace of EAD, what we need, discipline, focus and a strong desire to study /.../ (Carmen)

(SD24) Since I started this course I stayed insecure if I have success in process learning, because I work all day, I have two kids and I must keep me taking care my family every night and just after that I can study. (Genoveva)

(SD25) Thus, the distance learning course demands time, dedication. It is an illusion to think about or teach a distance course for lack of time. We risk say that in distance learning participants need to spend more time in the classroom teaching that course, because there is no alternative but to participate. (Valéria)

Ao colocar em cena dizeres que apontam para uma historicidade de descrédito, discriminação e marginalização em relação à EaD e em relação à decisão dos sujeitos em fazer tal curso (SD10, SD11, SD21, SD23, SD24, SD25), o discurso da seletividade aponta para um devir (SD10: promissing), em que efeitos de superação incidem na construção de um lugar legitimado para o professor pré-serviço de LI em EaD. Nas sequências, vê-se que as TICs funcionam ideologicamente de forma a selecionar o perfil dos participantes, uma vez que só conseguiriam permanecer no curso aqueles que possuem disciplina, capacidade de autoestudo, compromisso, engajamento.

Entendemos que esse discurso se configura em um movimento de resistência do sujeito em relação às vozes histórico-sociais que ressoam dizeres de que cursos 
universitários a distância não têm tanta credibilidade quanto os presenciais. Portanto, ao evocar o discurso da seletividade, o sujeito constrói para si um lugar de legitimidade e autoridade de forma a garantir e valorizar o exercício de sua (futura) profissão e, consequentemente, de sua identidade (ainda que fluida) como professor de LI cujo processo de formação se deu em ambiente virtual.

É interessante notar que, apesar da discursividade sócio-histórica que circula provocando efeitos de euforia, celebração e inovação acerca do uso de recursos tecnológicos nos processos educacionais (CASTRO NETTO, 2014; BAPTISTA, 2014; DIAS, 2012; QUEIROZ, 2004), os cursos universitários na modalidade não presencial ocupam ainda um lugar à margem, às vezes com pouca visibilidade inclusive nas instituições em que são desenvolvidos. Dessa forma, falar/enunciar sobre a formação em $\mathrm{EaD}$ é evocar um imaginário de um lugar (virtual?) 'sem fronteiras' (que dá poderes ao sujeito), mas, ao mesmo tempo, 'com restrições' (que submete o sujeito ao olhar e aprovação do outro). Assim, o sujeito estabelece uma relação de alteridade com sua formação em EaD de forma tensa e conflituosa, que o faz enunciar por mecanismos de contradição.

\subsection{SOBRE OS PROCESSOS DE ENSINO-APRENDIZAGEM DE LI EM UM CURSO DE LETRAS EAD}

Para compreender as representações sobre os processos de ensino-aprendizagem de LI construídas pelos professores pré-serviço em EaD, elencamos dois discursos. A saber: o discurso da falta e o discurso da excelência da tecnologia.

$\mathrm{O}$ discurso da falta é evocado para se referir à não suficiência de: (i) proficiência na LI, em especial no que diz respeito à produção oral; e (ii) interações síncronas, o que nos permite entrever o desejo do 'domínio' da LI (entendido como apropriação de fluência) e a percepção da falta. Vejamos os enunciados 'a' e 'b' e suas respectivas SDs:

a) o ensino-aprendizagem de LI, e em especial da oralidade, em EaD é lacunar

(SD26) My expectations were fulfilled. I developed my English written and reading greatly in this course. /.../ On the other hand, despite we use tools like Skype and Oovoo, our chat moodle has never worked adequately. Several chats had to be canceled. (Daniel)

(SD27) Indeed, our expectations were frustrated in terms we left the course Letra- English EAD / UFU, speaking, writing and listening as if we were on a short course of languages. (Milena)

(SD28) /.../ I felt a little frustrated because I had the pretense of learning the English language /.../ (Filomena)

(SD29) /.../ when it is to learning English, I believe that learning in the classroom is more effective than distance learning (Emília)

(SD30) /.../ I've developed my writing skill, but I really miss the speaking skill. (Rute)

(SD31) /.../ we learn very little in this course /.../ I thought that I would learn the language English (reading, writing, speaking and listening). We learn until some techniques of the reading, writing, speaking, listening but not the sufficient. So my expectations were not met /.../. (Milena) 
(SD32) I also think that relation to learning English language, in my opinion we learn very little in this course. (Carmen)

(SD33) My expectations still do not been fulfilled for the reason that I have not accuracy in English and I would like be better. (Genoveva)

(SD34) My expectations about the course were not well reached /.../ The most difficult chalenge in this course is to promote conversation and oral practice, this is something complicated, however it would be solved with conferences only in English. (Armando)

(SD35) And even now I speak little English, my expectations are frustrating. /.../ I have many difficulties and limitations as read English, write English texts, videos and listening in English. (Miriam)

(SD36) I have great difficulty in oral language, that is to say, I don't know if it's the shame or shyness, but I can't express myself correctly in a second language. (Meiry)

O desejo pela oralidade na LI e a construção de um imaginário de fluência pelo aprendiz de línguas estrangeiras têm sido problematizados em vários trabalhos (GUILHERME, 2008; BRITO; GUILHERME, 2014; NEVES, 2002; RAJAGOPALAN, 2005). Todavia, nesse contexto específico de formação de professores a distância, o anseio pela produção oral também produz efeitos, no fio do discurso, pela relação dialógica que estabelece com os dizeres acerca das práticas de compreensão e produção escritas.

Arriscaríamo-nos a dizer que esse ciberespaço de formação de professores produz um discurso do excesso da escrita, que funciona dialogicamente com o discurso da falta de oralidade, asseverando a relação 'excesso de escrita' e 'falta de oralidade', como se vê nas SDs abaixo:

(SD37) The only difficulty I really had is that I have more work involved because the majority of our communication with the teacher is through writing. (Socorro)

(SD38) /.../ and had a lot of difficulties for more writing assignments, because most of our communication with the instructor is through writing /.../ (Laura)

O discurso do excesso da escrita lança luz para um aspecto comumente apagado na discursividade pedagógica acerca dos processos de ensino-aprendizagem mediado por computadores, a saber: as limitações institucionais e mesmo tecnológicas, as quais estabelecem, em grande medida, o que pode e o que deve ser feito nesse contexto. Se comparadas às práticas de interação face a face, as práticas de linguagem por meio da escrita (fóruns, chats, wikis, compilação de glossário), em um ambiente formal de ensinoaprendizagem, impõem demandas outras ao sujeito, exigindo, por exemplo, que ele leia as produções dos colegas e que invista um maior trabalho de elaboração de seu dizer. Demanda essa asseverada pelo fato de que a escrita produz um efeito de memória do dizer, eternizando os posicionamentos no ciberespaço. A escrita coloca, então, uma forma outra de interação professor-aluno-tutor, resultando em reconfigurações na relação dos sujeitos com o saber. 
b) o ensino-aprendizagem da LI em EaD é prejudicado pela falta de interações sincronas

(SD39) /.../ sometimes there is an extremely large period of time, in terms of response in these interactions, and this may compromise this process. I think there is still a lack of direct interaction between student and teacher. (Jairo)

(SD40) I try to compensate that on the internet, but real conversations will be much better. (Rute)

(SD41) I miss of real activities like chats (for example to train English conversation or grammar) /.../ (Sabrina)

(SD42) The virtual environment meets very well the role of facilitating the interactions and discussions between students and tutors. But I think it lacks a more direct link between students and teachers regarding the pronunciation of the English language. I believe that the courses should avail a little more available technologies to stimulate a more real contact of students with English. (Emanuel)

(SD43) Although the course is rich in knowledge, I also think it lacks a little more interaction between students and even teachers to practice the English language. (Emanuel)

O discurso da falta da proficiência oral é asseverado pelo discurso de que o curso a distância não propicia interações presenciais ou de forma mais síncrona (por meio de webconferências, por exemplo), com vistas a promover, assim, o 'real' contato dos professores pré-serviço com a língua. Essa representação parece apontar para o desejo do outro, desejo de um saber que poderia ser apropriado na relação com aquele que se supõe saber mais (professor, tutor) e que, portanto, pode balizar/avaliar a produção oral do professor em formação.

Não podemos deixar de mencionar que o discurso da falta (de conhecimento da LI e de interações síncronas) se confronta com o discurso da autonomia, desfacelando a ilusão de que 'se pode tudo'. Ainda que se inscreva na (ilusão) da autonomia que um curso EaD demanda, essa autonomia não é suficiente para que se atenda, por exemplo, às exigências de escrita do curso. Um embate de vozes, assim, se deflagra, fazendo que o sujeito, por meio da contradição, construa uma discursividade que pulsa entre a imagem que tem de si (sou autônomo) e a imagem que gostaria de ter de si (gostaria de atender às demandas de escrita do curso). Uma alteridade tenso-conflitiva que, mais uma vez, marca a posição do sujeito no processo de ensino-aprendizagem e de formação via $\mathrm{EaD}$.

Finalmente, o discurso da excelência da tecnologia, representado pelo enunciado $o$ ensino-aprendizagem em EAD é potencializado pela multiplicidade de recursos, conforme as sequências abaixo:

(SD44) /.../ only a distance course allows this kind of immersion and involvement /.../ the whole virtual environment begins to make part of a daily routine of the student $/ . . . /$ becomes more natural and easy for him. (Jairo)

(SD45) I found it an ideal place for learning, teaching, and living a college experience; where I can freely discuss ideas /.../ also provides me with leadership and fellowship opportunities /.../ (Socorro)

(SD46) With the distance learning course I feel prepared to act as teacher. (Margarida)

(SD47) In the virtual environment with the tools that the course offered: being possible the acquisition of shared knowledge, interact and learn to live in a group /.../ (Milena) 
(SD48) /.../ I barely knew how to send emails /.../ this platform gave me a huge range of new knowledge and learning /.../So I fully trust this technological innovation for education. (Filomena)

(SD49) /.../ especially computers and the internet, are bound to their potential to promote intra and interpersonal interaction, communication, exchange of experiences and knowledge, research opportunities /.../ (Filomena)

(SD50) For those who like to study and loves challenges and ideal course EAD. (Carmen)

(SD51) The virtual environment meets very well the role of facilitating the interactions and discussions between students and tutors. (Emanuel)

(SD52) Contrary to what many think, distance learning is not solitary. /.../ The dynamics of the activities may also be responsible for stimulating the cooperation between participants increases the sense group and, consequently, in most cases, motivation. (Valéria)

O discurso da excelência da tecnologia apaga a relação do sujeito com a LI e a desloca para a relação com a tecnologia, compensando, assim, o discurso da falta por meio de uma voz que enuncia 'não aprendi a LI, mas aprendi a lidar com recursos tecnológicos'. Trata-se de um discurso que se sustenta interdiscursivamente no imaginário de que a tecnologia por si mesma é capaz de promover o ensino-aprendizagem da língua para o sujeito que ocupa um lugar na pós-modernidade. Tal saber-poder tecnológico seria, portanto, condição sine qua non para que esse sujeito instaurasse uma relação de pertencimento com o mundo globalizado. Nessa suposta relação de causaefeito, o saber-poder tecnológico garantiria o saber-poder pedagógico. A inscrição nessa discursividade funciona, também, como forma de resistência ao discurso de não legitimação dos cursos $\mathrm{EaD}$, já que inscreve o sujeito num mundo contemporâneo que demanda do professor competência técnica e letramento digital.

Vale salientar que esse discurso funciona pelo mecanismo enunciativo do esquecimento, em que o sujeito 'se esquece' de toda sua história de interação verbal vivenciada em cursos presenciais. Respaldam-se, pois, dizeres que celebram a possibilidade de interação entre os participantes da plataforma virtual de aprendizagem, colocando o ciberespaço como lugar de compartilhamento, colaboração, cooperação, como se a interação verbal não fosse um aspecto constitutivo de todo e qualquer processo de ensino-aprendizagem (SD47, SD49, SD51, SD52).

Vêm também à tona dizeres que fazem ressoar sentidos de completude para a experiência de ensino-aprendizagem a distância, o que, como visto no discurso da seletividade, legitima um espaço de saber-poder para o sujeito (SD44, SD45, SD46, SD48).

O que se pode entrever pelas SDs é, mais uma vez, a contradição que se deixa revelar por meio de uma relação tensa que os sujeitos estabelecem com sua formação. Há nos dizeres um batimento entre presença e ausência, entre a representação de ciberespaço como lugar de interação e lugar de ausência. Ausência advinda da percepção da falta, do desejo de completude no/pelo outro, da presença do professor.

\section{CONSIDERAÇÕES FINAIS}

Ao lançar um gesto de interpretação aos dizeres sobre a formação em Letras-Inglês e os processos de ensino aprendizagem de LI de professores pré-serviço em um curso a distância, buscamos analisar as representações construídas por esses sujeitos. 
Ocupando diferentes posições, vê-se que os sujeitos produzem discursos que não são estanques ou isolados, antes se relacionam/imbricam uns com os outros, constituindose no jogo de unidade e dispersão dos sentidos. Em outras palavras, as representações delineadas se sobrepõem, se complementam e se confrontam pelo embate das diversas vozes sócio-histórico-ideológicas evocadas pelos sujeitos ao enunciarem sobre sua experiência com o ensino-aprendizagem de LI a distância. O movimento dos discursos se marca pela contradição e heterogeneidade: a EaD, ao mesmo tempo que proporciona também impõe uma autonomia aos sujeitos, a qual, por sua vez, beneficia, mas seleciona seus participantes. Ademais, apesar da falta que a marca, a EaD aparece discursivizada como lugar de excelência.

Essa discursividade se movimenta produzindo efeitos que corroboram algumas dicotomias, a saber: tradição x inovação; presença x ausência; aluno de curso presencial $\mathrm{x}$ aluno de curso em EaD; real x virtual; individualismo x interação, como se a relação curso presencial-curso a distância se configurasse como uma polaridade (em que, aliás, um dos elementos é tido como superior ao outro).

A fragilidade das dicotomias pode ser observada, por exemplo, pela inscrição, tanto por professores pré-serviço em cursos presenciais quanto por aqueles da modalidade a distância, no discurso da falta e o movimento de resistência a ela, o que traz à baila a natureza cindida e fragmentada dos sujeitos. Escamoteia-se para esses o fato de que a relação com uma língua outra (e seu possível 'domínio') tem a ver com o desejo,

\footnotetext{
O desejo do e pelo outro, o desejo de ser o desejo do outro e, ao mesmo tempo, o desejo de ser o outro, que "imagina" (representa) como ideal, constitui uma das marcas mais relevantes, senão a mais importante, que impulsiona o sujeito na sua busca incessante pelo preenchimento da falta que o constitui. É o que resta (sobra, objeto a) que nos move em direção ao outro do imaginário. (CORACINI, 2014, p. 16)
}

Finalmente, cumpre salientar que, ainda que programas governamentais como o PARFOR oportunizem o acesso à educação de nível superior, com vistas à inclusão sóciolinguístico-digital (HASHIGUTI; BRITO, 2014), é preciso criar espaços de interação verbal, ao longo do próprio curso, para que as imagens construídas pelos sujeitos sejam problematizadas, possibilitando-lhes entrever a linguagem enquanto materialidade discursiva e ideológica; espaços de enfrentamento que possibilitem o desarranjo da rede de sentidos na qual o sujeito professor constitui sua identidade, chamando-o "a se reposicionar, a se identificar a novos sentidos que sustentem a construção imaginária do eu" (TAVARES, 2010). Trata-se, conforme Riolfi (2011) de "provocar o distanciamento do professor em formação das matrizes de sentido que organizam suas memórias" (p. 113), de "levar aquele que está sendo formado a alterar sua relação com suas palavras" (p. 122), (des)arranjando, assim, a configuração de uma memória congelada.

Consonante com o trabalho de Guilherme (2010, p. 199), os resultados deste estudo também acenam para a

necessidade de se incluir, na formação pré e em-serviço um espaço de trabalho com a linguagem que contemple o funcionamento das representações nos processos discursivos, que contemple a língua enquanto materialidade discursiva e ideológica. Apontam, também, 
para a necessidade de um trabalho que contemple a construção da subjetividade do professor brasileiro de LI pré e em-serviço, subjetividade esta comumente apagada, silenciada, esquecida e denegada. Apontam, ainda, para a necessidade de um trabalho que possa promover deslocamentos nas inscrições discursivas dos sujeitos em-formação, dos sujeitos formados e dos sujeitos-formadores.

É, pois, preciso que professores formadores e tutores atentem para a necessidade de um trabalho que contemple a subjetividade do professor em formação, no ambiente virtual, tentando promover deslocamentos em suas inscrições discursivas na medida em que essas podem incidir em sua futura prática pedagógico-educacional. Finalmente, é também preciso pensar como as discursividades podem contribuir para apontar caminhos outros, diferentes olhares e formas de se conceber os próprios processos de formação de professores de línguas em nosso país.

A interface aqui proposta não deve de forma alguma ser vista como a mera aplicação de conceitos discursivos aos trabalhos realizados na LA, mas como possibilidade de "deslocamento no escopo epistemológico desses campos de conhecimento para constituir um amálgama teórico suficientemente complexo e indisciplinar" (BRITO; GUILHERME, 2013, p. 26, grifo das autoras). Ao mesmo tempo em que a LA dialoga com os estudos discursivos para melhor compreender a constituição dos sujeitos e da linguagem, nos contextos de formação de professores e ensinoaprendizagem de línguas, a LA, por outro lado, pode ampliar, para os estudos do discurso, questões que tangenciam o funcionamento do discurso pedagógico-educacional.

\section{REFERÊNCIAS}

BAKHTIN, M. (1920). Para uma filosofia do ato responsável. Trad. Valdemir Miotello e Carlos Alberto Faraco. São Carlos: Pedro \& João Editores, 2010.

; VOLOSHINOV, V. N. (1929). Marxismo e Filosofia da Linguagem: problemas fundamentais do Método Sociológico na Ciência da Linguagem. Trad. Michel Lahud e Yara Frateschi Vieira. 9. ed. São Paulo, Hucitec, 2002.

BAPTISTA, J. B. Reflexões de professores de inglês em formação inicial sobre o uso de novas tecnologias. Revista Brasileira de Linguística Aplicada, v. 14, n. 3, p. 533-552, 2014.

BOHN, H. Linguística Aplicada e Contemporaneidade. In: FREIRE, M.; ABRAHÃO, M. H. V.; BARCELOS, A. M. F. (Org.) Linguística Aplicada e Contemporaneidade. Campinas: Pontes, 2005. p. 11- 23.

BRITO, C. C. P.; GUILHERME, M. F. F. Memorial de aprendizagem e a formação do professor: vozes constitutivas da relação aprender/ensinar línguas estrangeiras. Revista Brasileira de Linguística Aplicada, v. 14, n. 3, p. 511-532, 2014.

Linguística Aplicada e Análise do Discurso: possíveis entrelaçamentos para a constituição de uma epistemologia. Cadernos Discursivos, Catalão, v. 1, n. 1, p. 17-40, 2013.

; HASHIGUTI, S. T.; PEIXOTO, M. R. B. S. As novas tecnologias da informação e da comunicação (NTICs) no ensino de língua inglesa. Uberlândia: UFU, CEaD, 2015.

CASTRO NETTO, M. Novas tecnologias na discursividade da linguística aplicada: ensinoaprendizagem de língua inglesa. João Pessoa: Novas Edições Acadêmicas, 2014.

CORACINI, M. J. Entre adquirir e aprender uma língua: subjetividade e polifonia. Bakhtiniana, v. 9, n. 2, p. 4-24, 2014.

DIAS, R. WebQuests: Tecnologias, multiletramentos e a formação do professor de inglês para a era do ciberespaço. Revista Brasileira de Linguística Aplicada, v. 12, n 4, p. 861-882, 2012. 
GREGOLIN, M. R. V. Bakhtin, Foucault e Pêcheux. In: BRAIT, B. (Org.). Bakhtin: outros conceitoschave. São Paulo: Contexto, 2006. p. 33-52.

GUILHERME, M. F. F. Bakhtin e Pêcheux: atravessamentos teóricos. In: PAULA, L.; STAFUZZA, G. (Org.). Círculo de Bakhtin: pensamento interacional. Campinas, SP: Mercado de Letras, 2013. p. 259279.

Da formação pré-serviço à prática em-serviço do professor de língua inglesa: a falta constitutiva. Trabalhos em Linguística Aplicada, v. 49, n. 1, p. 185-204, 2010. $\overline{41,2009}$.

Discursividade dialógico-polifônica na formação de professores. Bakhtiniana, v. 1, n. 1, p. 23 -

Competência oral-enunciativa em língua estrangeira (inglês): fronteiras e limites. 2008. 311f. Tese (Doutorado em Linguística Aplicada e Estudos da Linguagem) - Pontifícia Universidade Católica de São Paulo, São Paulo, 2008.

; SANTOS, J. B. C. Letramento em língua inglesa: uma reflexão bakhtiniana a partir de um estudo de caso. Bakhtiniana, v. 9, n. 2, p. 52-71, 2014.

HASHIGUTI, S. T.; BRITO, C. C. P. English Learning at a Distance: a case study on social-linguistic and digital inclusion. Proceedings of the 2nd Global Multidisciplinary e-Conference, p. 149-160, 2014. HENRY, P. Os fundamentos teóricos da ‘análise automática do discurso' de Michel Pêcheux (1969). In: GADET, F. e HAK, T. (Org.). Por uma análise automática do discurso: uma introdução à obra de Michel Pêcheux. Trad. Bethania S. Mariani [et. al.]. 4. ed. Campinas, SP: Editora da Unicamp, 2010. p. 11-38.

KLEIMAN, A. B. Agenda de pesquisa e ação em Linguística Aplicada: problematizações. In: Moita Lopes, L. P. (Org.). Linguística Aplicada na modernidade recente: festschrift para Antonieta Celani. São Paulo: Parábola, 2013. p. 39-58.

LIMA, T. A.; MASCIA, M. A. A. (Re)torcendo os fios do discurso político educacional da EaD: uma análise dos documentos do MEC. In: CORACINI, M. J. et al. (Org.). Da letra ao píxel e do pixel à letra: uma análise discursiva do e sobre o virtual: identidade, leitura e escrita, formação de professores e ensinoaprendizagem de línguas. Campinas, SP: Mercado de Letras, 2011. p. 261-283.

LUZ, E. P. B. A autonomia no processo de ensino e aprendizagem de línguas em ambiente virtual (teletandem). 2009. 230f. Dissertação. (Mestrado em Estudos Linguísticos). Universidade Estadual Paulista Júlio de Mesquista Filho, 2009.

MOITA LOPES, L. P. Da aplicação de linguística à linguística aplicada indisciplinar. In: Pereira, R. C. e Roca, P. (Org.). Linguística aplicada: um caminho com diferentes acessos. São Paulo: Contexto, 2009. p. 11-24.

Lingüística Aplicada e vida contemporânea: problematização dos construtos que têm orientado a pesquisa. In: 85-107. (Org.). Por uma Linguística Aplicada Indisciplinar. São Paulo: Parábola, 2006. p.

NEVES, M. S. Processo discursivo e subjetividade: vozes preponderantes na avaliação da oralidade em língua estrangeira no ensino universitário. 2002. 276f. Tese (Doutorado em Linguística Aplicada). Universidade Estadual de Campinas, Campinas, 2002

PAIVA, V. L. M. Tecnologia na docência em línguas estrangeiras: convergências e tensões. In: SANTOS, L. L. C. P. (Org.) Convergências e tensões no campo de formação e do trabalho docente. Belo Horizonte: Autêntica, 2010. p. 595-613. Disponível em <http://www.veramenezes.com/endipe.pdf > Acesso em: 12 out. 2015.

O. O papel da educação a distância na política de ensino de línguas. In: MENDES et alii (Org.). Revisitações: edição comemorativa: 30 anos da Faculdade de Letras/UFMG. Belo Horizonte: UFMG/FALE, 1999. p. 41-57.

PÊCHEUX, M. (1969). Análise Automática do Discurso (AAD-69). In: GADET, F; HAK, T. (Org.). Por uma Análise Automática do Discurso: uma introdução à obra de Michel Pêcheux. Trad. Bethania S. Mariani et al. 3. ed., Campinas: Editora da Unicamp, 1997. p. 61-105.

(1975). Semântica e Discurso: uma crítica à afirmação do óbvio. Trad. Eni Orlandi. Campinas: Ed. da UNICAMP, 1997.

PENNYCOOK, A. Uma linguística aplicada transgressiva. In: MOITA LOPES, L. P. (Org.). Por uma linguística aplicada INdisciplinar. São Paulo: Parábola Editorial, 2006. p. 67-84.

BRITO, Cristiane Carvalho de Paula; GUILHERME, Maria de Fátima Fonseca. A constituição do professor de Inglês pré-serviço em um Curso de Letras EaD: representações sobre formação, ensino-aprendizagem e tecnologia. Linguagem em (Dis)curso - LemD, Tubarão, SC, v. 17, n. 1, p. 117-136, jan./abr. 2017. 
QUEIROZ, E. S. C. Educação a distância: uma investigação sobre possíveis contribuições para a educação continuada de professores de língua estrangeira (Inglês). Revista Brasileira de Linguística Aplicada, v. 4, n. 2, p. 11-44, 2004.

RAJAGOPALAN, K. Non-native speaker teachers of English and their anxieties: ingredients for an experiment in action research. In: LLURDA, E. (Ed.). Non-native Language Teachers. Perceptions, Challenges and Contributions to the Profession. New York: Springer, 2005. p. 283-303.

REVUZ, C. A língua estrangeira entre o desejo de um outro lugar e o risco do exílio. In: SIGNORINI, I. (Org.). Lingua(gem) e identidade. São Paulo: Mercado de Letras, 1998. p. 213-230.

RIOLFI, C. R. Além do passado congelado: o equívoco na formação de professores de língua materna. In: CORACINI, M. J.; GHIRALDELO, C. M. (Org.). Nas malhas do discurso: memória, imaginário e subjetividade. Campinas: Pontes, 2011.p. 111-138.

ROCHA, C. H.; MACIEL, R. F. (Org.). Língua estrangeira, formação cidadã e tecnologia: ensino e pesquisa como participação democrática. In: Língua estrangeira e formação cidadã: por entre discursos e práticas. 2. ed. Campinas, SP: Pontes Editores, 2015. p. 13-29.

RUIZ, E. M. S. D. Material didático de educação a distância, neoliberalismo e autonomia: relações (im)possíveis. Calidoscópio. v. 11, n. 3, p. 297-305, 2013.

SANTOS, J. B. C. Uma reflexão metodológica sobre análise de discursos. In: FERNANDES, C. A. e SANTOS, J. B. C. (Org.). Análise do Discurso: unidade e dispersão. Uberlândia: EntreMeios, 2004. p. $109-118$

Por uma Teoria do Discurso Universitário Institucional. 2000. 236f. Tese (Doutorado em Estudos Linguísticos). Universidade Federal de Minas Gerais. 2000.

et al. Introdução aos estudos bakhtinianos. In: FERNANDES, C. A. e SANTOS, J. B. C. (Org.). Teorias linguísticas: problemáticas contemporâneas. Uberlândia: Edufu, 2003. p. 35-44.

SILVA, M. R.; BRITO, C. C. P. Discurso, tecnologia e ensino-aprendizagem de língua: um olhar para os dizeres nos estudos da Linguística Aplicada. Catalão: UFG, 2015. (Comunicação Oral)

SZUNDY, P. T. C. Educação como ato responsável: a formação de professores de linguagens à luz da filosofia da linguagem do círculo de Bakhtin. Trabalhos em Linguística Aplicada, v. 53, n.1, p. 13-32, 2014.

TAVARES, C. N. Identidade itine(r)rante: o contínuo (des)apropriar-se do lugar de professor de língua estrangeira. 2010. 279f. Tese (Doutorado em Linguística Aplicada). Instituto de Estudos da Linguagem, Universidade Estadual de Campinas, Campinas, 2010.

; CHAGAS, L. A. Efeitos do discurso das novas tecnologias na constituição identitária do professor de línguas. Revista Escrita, n. 15, p. 1-16, 2012.

WHITE, C. Language Learning in Distance Education. Cambridge: Cambridge University Press, 2003.

Recebido em: 22/07/16. Aprovado em: 16/01/2017.

Title: Pre-service English teacher constitution in a language distance course: representations of education, teaching-learning and technology

Authors: Cristiane Carvalho de Paula Brito; Maria de Fátima Fonseca Guilherme

Abstract: This paper aims, from a discursive perspective of language in interface with the studies developed in Applied Linguistics, at investigating representations constructed in utterances by pre-service English teachers about their education process and about their English teaching-learning process at a distance English Language Teacher Education Course. The results point out that the participants enunciate from an in-between place, marked by the clash between the pre-service English teacher-subject position in a presential course and pre-service English teacher-subject position in a distance course. In this clash, they inscribe themselves in the discourse of autonomy, of selectivity, of lack and of the excellence of technology, which build effects of truth that obliterate the conflictive and contradictory aspects that are constitutive of the relation subject-language-technology.

Keywords: Discourse. Technology. Teacher education.

BRITO, Cristiane Carvalho de Paula; GUILHERME, Maria de Fátima Fonseca. A constituição do professor de Inglês pré-serviço em um Curso de Letras EaD: representações sobre formação, ensino-aprendizagem e tecnologia. Linguagem em (Dis)curso - LemD, Tubarão, SC, v. 17, n. 1, p. 117-136, jan./abr. 2017. 
Título: La constitución del profesor de inglés pre-servicio en un Curso de Letras EaD: representaciones sobre formación, enseñanza y aprendizaje y tecnología

Autores: Cristiane Carvalho de Paula Brito; Maria de Fátima Fonseca Guilherme

Resumen: Este trabajo tiene el objetivo, desde una perspectiva discursiva de lenguaje en interface con los estudios en Lingüística Aplicada, de investigar representaciones construidas en el que es dicho por profesores pre servicio sobre el proceso de formación y de enseñanza y aprendizaje de lengua inglesa en un curso de licenciatura de Letras-Inglés (LI) a distancia. Los resultados apuntan que los participantes enuncian de un lugar de entremedio, marcado por el embate entre la posición sujeto-profesor pre servicio de LI en curso presencial y la posición sujeto-profesor pre servicio de LI en curso EaD. En ese embate, ellos se inscriben en el discurso de la autonomía, de la selectividad, de la falta y de la excelencia de la tecnología, los cuales funcionan de forma a crear efectos de verdad que obliteran los aspectos de contradicción y conflictivos constitutivos de la relación sujetolenguaje-tecnología.

Palabras-clave: Discurso. Tecnología. Formación docente.

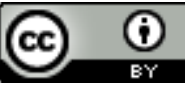

Este texto está licenciado com uma Licença Creative Commons Atribuição 4.0 Internacional.

BRITO, Cristiane Carvalho de Paula; GUILHERME, Maria de Fátima Fonseca. A constituição do professor de Inglês pré-serviço em um Curso de Letras EaD: representações sobre formação, ensino-aprendizagem e tecnologia. Linguagem em (Dis)curso - LemD, Tubarão, SC, v. 17, n. 1, p. 117-136, jan./abr. 2017. 